\title{
Methodology of project management at implementation of projects of high-rise construction
}

\author{
Oksana Papelniuk ${ }^{1, *}$ \\ ${ }^{1}$ Moscow State University of Civil Engineering, Yaroslavskoye shosse 26, Moscow, 129337, Russia
}

\begin{abstract}
High-rise construction is the perspective direction in urban development. An opportunity to arrange on rather small land plot a huge number of the living and commercial space makes high-rise construction very attractive for developers. However investment projects of high-rise buildings' construction are very expensive and complex that sets a task of effective management of such projects for the company builder. The best tool in this area today is the methodology of project management, which becomes a key factor of efficiency.
\end{abstract}

\section{Introduction}

Today it is impossible to underestimate influence of high-rise construction on formation of a modern city landscape and also importance of the innovative technologies which are applied at their construction. The conventional criteria in the world according to which the building can carry the proud name "skyscraper" have been established by Council for highrise buildings and the urban environment. According to classification of the organization, a skyscraper - the building not less than 150 meters high, and multi-storey buildings higher than 300 meters it is accepted to carry to ultrahigh.

By the end of 2015 on the planet there was the 3214th skyscraper, from them 56 ultrahigh, construction of 300 more similar buildings among which 90 will rise by height more than 300 meters was also conducted.

However implementation of similar investment and construction projects is very expensive and difficult, hiding in itself a lot of calls for construction company. Construction even of a usual, not ultrahigh skyscraper costs the company builder in the sum not less than 80 million dollars. And in case of construction of champions on height can reach 700-800 million dollars. Expensive researches begin even prior to construction - development, careful check and the approval of the project of future building, part in which is taken only by highly skilled engineers and architects, studying of the place of alleged construction taking into account "wind loadings", features of soil, a seismological situation in the area demand considerable expenses. Then even more essential expenses on laying of the strongest base, operation and the maintenance of the construction equipment and also compensation to thousands of workers begin.

\footnotetext{
*Corresponding author: oksana-17@mail.ru
} 
The complexity and cost intensity of such projects sets a task of use of the most effective methods of management therefore use of tools of project management gains ground at implementation of similar projects for the company builder. Today the methodology of project management is universal, and can be successfully used in various spheres and branches, including high-rise construction.

\section{Materials and Methods}

In methodology of project management the project is considered as a system of the purposes and mechanisms of realization in the form of technological, technical and organizational documentation, regulation processes by material, technical, labor and other resources for achievement of goals.

The concept of project management is mainly described by means of the following main structural and functional components:

- context of project management;

- processes of project management;

- main functions of project management;

- methods of project management;

- practice and effective management of the project.

Disclosure of a being of these components of structure can be tracked by the analysis of structure of knowledge and components of project management which are submitted in figure 1 .

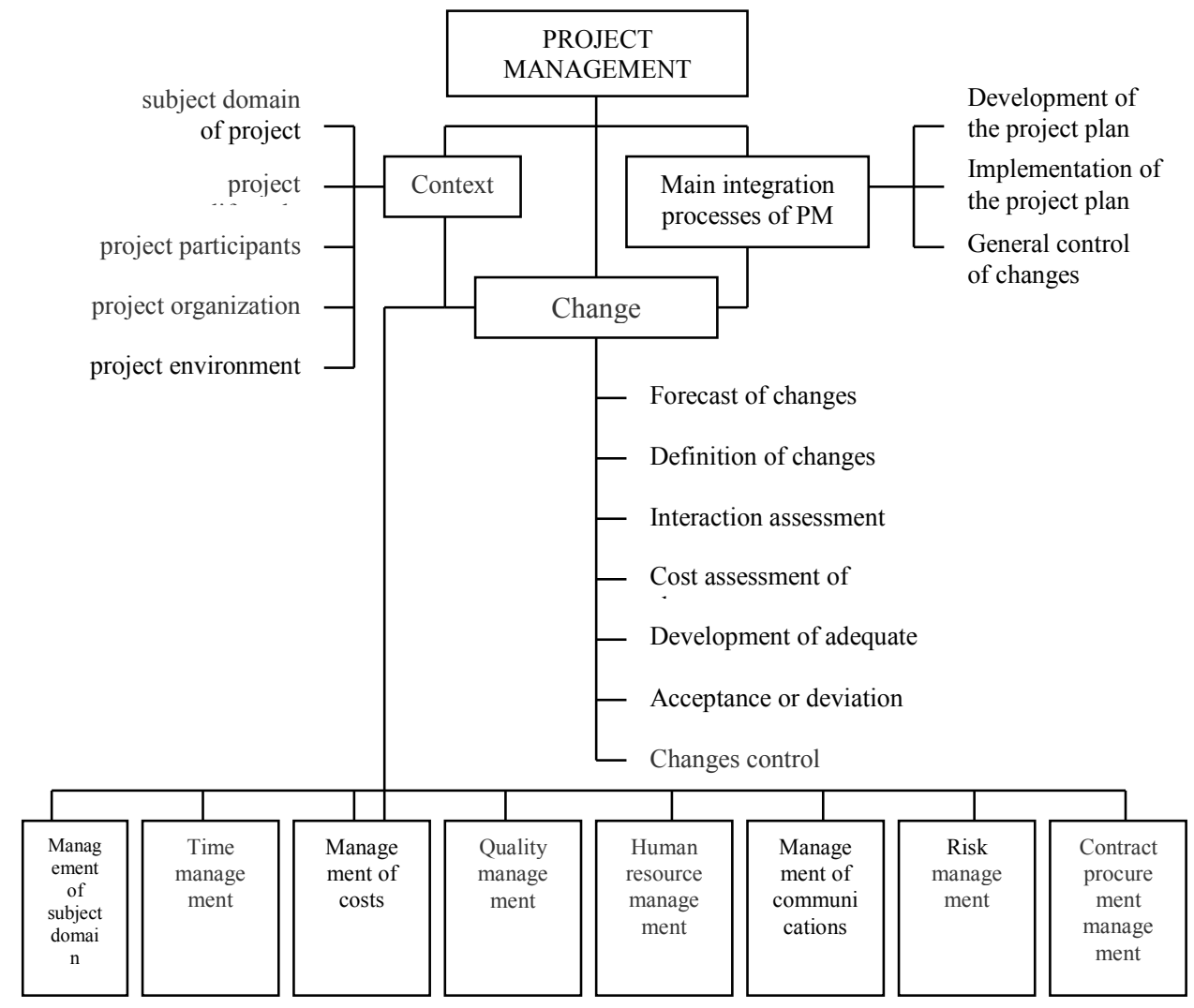

Fig. 1. Structure of knowledge and components of project management 


\section{Results}

The structure of project management given above is universal and can be used at implementation of projects of high-rise construction in which development and realization many participants of the project take part. Their structure is presented on figure 2 . But all of them, naturally, can't be presented in each specific project. Very often one participant can assume several functions of certain participants which are given figure 2 .

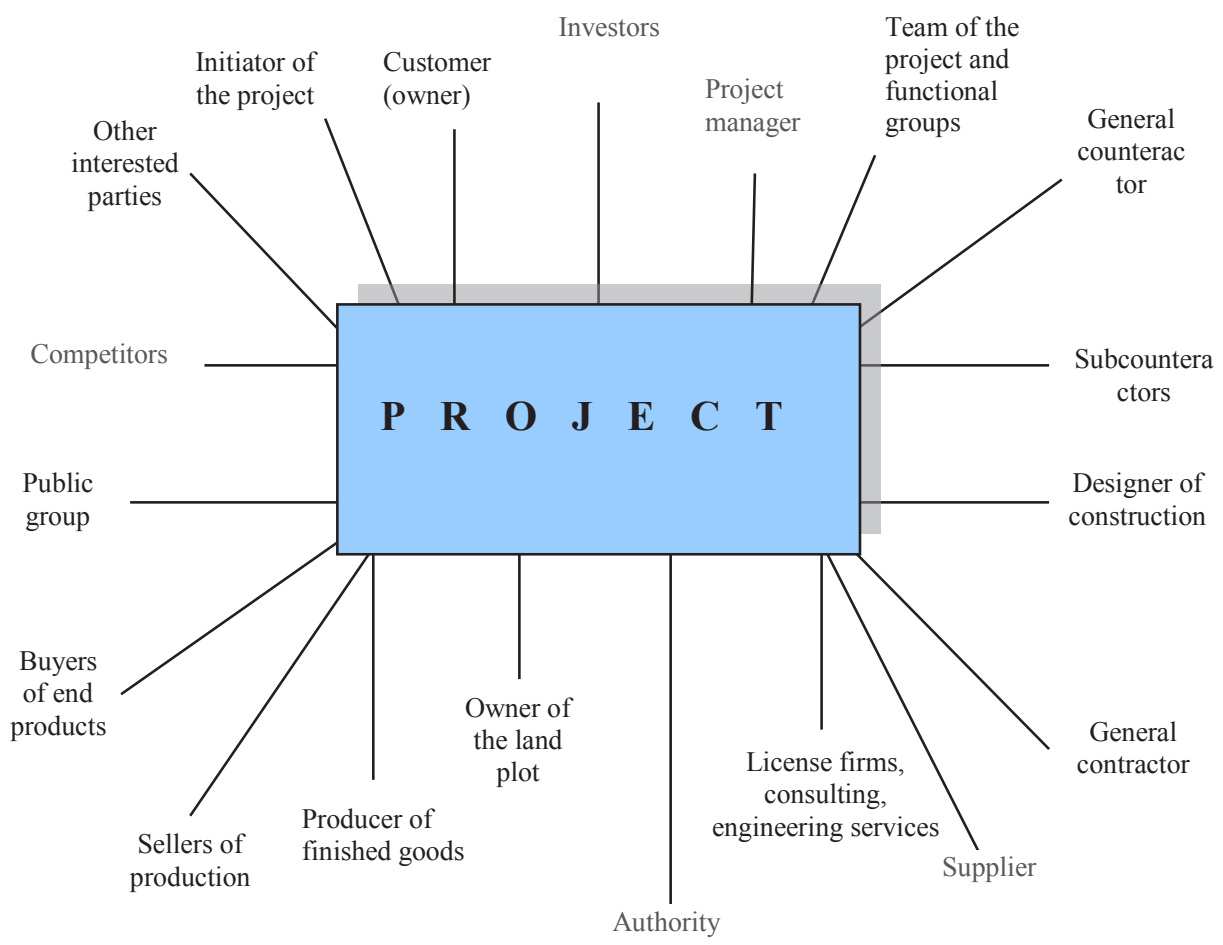

Fig. 2. Schematic diagram of participants of the project

In case of development of the system of project management its surrounding is considered. It is a set of the external and internal factors influencing project implementation $[1,2]$. In a general view factors and other internal variables of any organization (subjects of managing) can be traced according to figure 3 (figure 3 ).

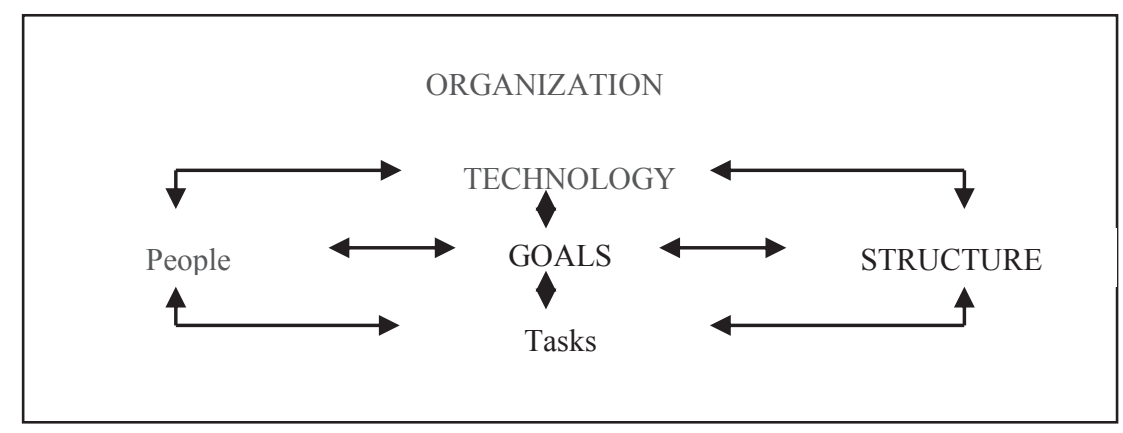

Fig. 3. Interrelation of internal variables of the organization 
The purpose is an end result. The object can be set by the management of the organization, as well as other factors of the internal environment of the organization realizing the project. All other components of the internal environment as a taxonomy to requirements of the purpose and the tasks following from this [3, 4].

\section{Discussions}

There is a question whether it is necessary to recognize the provided structure of the project management system of high-rise construction accepted for creation. According to some experts it is necessary to consider also such variable as financial resources [5]. And experts divide structure of factors of an external environment for the organization and a project management system into two components: direct and indirect influence. Composition of these two units, it is possible to see in figure $4[6,7]$.

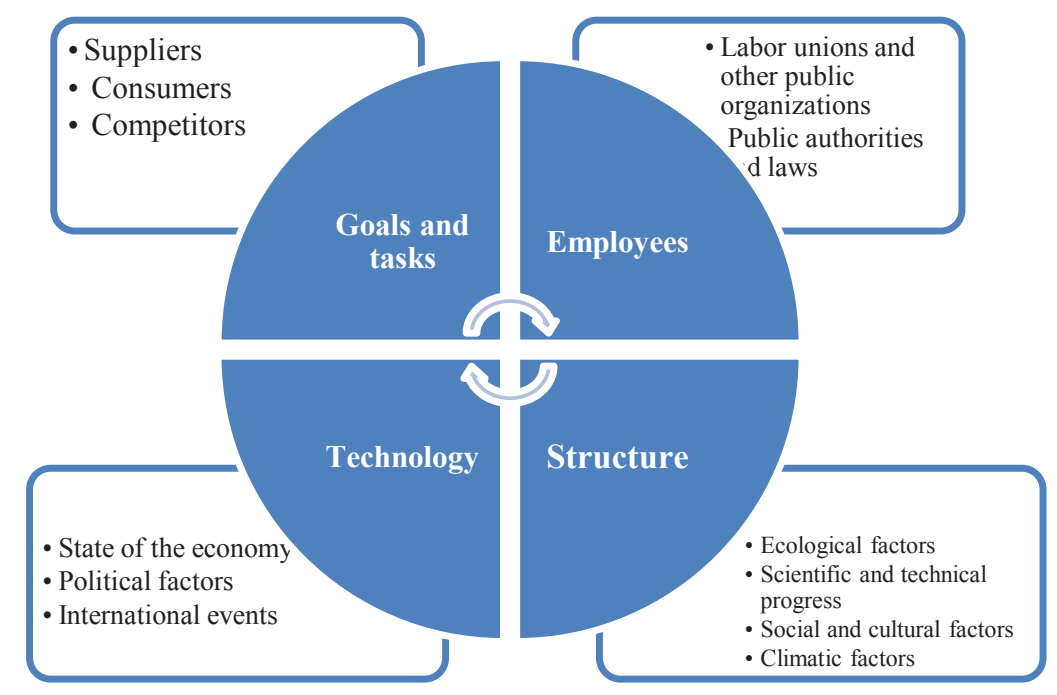

Fig. 4. Factors of the internal and external environment

\section{Conclusion}

Thus, high-rise construction is the direction of construction in which use of new technologies, introductions of progressive forms of the organization of production, use of modern materials is most intensively carried out. All this can't be rather effective without use of methodology management of investment and construction projects. The prevalence of investment and construction projects around the world imposes increased requirements to knowledge of management of them.

Construction is not only the first branch in which began to use provisions of the theory of project management, but also subject to introduction of new techniques and instruments of project management. Now project management is a key factor of efficiency and at implementation of projects of high-rise construction.

\section{References}


1. I.G. Lukmanova, A.G. Korolyov, E.V. Nezhnikova, Project Management, MGSU, (2013)

2. E. Nezhnikova. Procedia Engineering $165 \quad 1300-1304 \quad$ (2016) doi 10.1016/j.proeng.2016.11.854

3. N. Safronova, E. Nezhnikova, A. Kolhidov MATEC Web of Conferences 10608024 (2017) doi. 10.1051/matecconf/201710608024

4. E. Nezhnikova, R. Obukhov MATEC Web of Conferences 10608025 (2017) doi: $10.1051 /$ matecconf $/ 201710608025$

5. A. Larionov, E. Nezhnikova ARPN Journal of Engineering and Applied Sciences 3 2023-2029 (2016)

6. A. Larionov, E. Nezhnikova International Journal of Applied Engineering Research 6 4433-4439 (2016)

7. A. Jones, G. Fallon, R. Golov, European Business Review 12 (4) doi:10.1108/09555340010336871 